\title{
Some observations on an amoeba, destructive agent of the gills of Cerastoderma edule (Mollusca, Bivalvia)
}

\author{
Carlos Azevedo \\ Department of Cell Biology, Institute of Biomedical Sciences and IMAR - Institute of Marine Research, University of Oporto, \\ Largo A. Salazar no. 2, P-4050 Porto, Portugal
}

\begin{abstract}
The fine structure of an amoeba, a destructive agent found in sub-epithelial tissues of the gills of Cerastoderma edule (Mollusca, Bivalvia), is described. The uninuclear amoeba reached a diameter of 18 to $20 \mu \mathrm{m}$, and contained a prominent nucleolus about $3 \mu \mathrm{m}$ in diameter which seemed to be locus of active rRNA synthesis. Several dense extranucleolar bodies found at the periphery of the nuclear envelope may represent a nucleolar segregation, i.e. a structure similar to the nucleolus-like bodies. The appearance of these structures suggests they may be involved in the continuous transport of ribonucleoproteins. Histopathology associated with these cells revealed haemocytic infiltration and necrotic cells, which were interpreted as a sign that this amoeba was pathogenic to the host.
\end{abstract}

KEY WORDS: Ultrastructure - Amoeba - Destructive agent Bivalves

The life cycles and transmission of amoeboid cells infecting bivalves are unknown (Lauckner 1983), and very few descriptions have been given so far.

An amoeba in sub-epithelial tissues of the gills of the cockle Cerastoderma edule (Mollusca, Bivalvia), found by chance during a study on the life cycle of Unikaryon legeri, a microsporidian hyperparasite previously reported by Azevedo \& Canning (1987), is described below. Gaping specimens of $C$. edule, collected from the estuarine region of Aveiro (Portugal), were examined. Amoebas were observed in fresh preparations of gill tissues. Fourteen of 34 cockles $(41.2 \%)$ were infected and $9(26 \%)$ were simultaneously parasitized by metacercariae infected with the microsporidian $U$. legeri. Small fragments of infected gills were fixed in buffered $3.0 \%$ glutaraldehyde and post-fixed in buffered $2 \% \mathrm{OSO}_{4}$, then dehydrated in a graded series of ethanol and embedded in Epon according to standard techniques (Azevedo \& Canning 1987). For light microscopy (LM), semithin sections were stained with toluidine blue, and for transmission electron microscopy (TEM), ultrathin sections were double stained with uranyl acetate and lead citrate and examined in a Jeol 100 CXII TEM at $60 \mathrm{kV}$.

The presence of isolated and massive concentrations of amoebas was observed in the internal tissues of the gill filaments. Infiltration of the gill epithelium by amoebas and host haemocytes was only rarely observed in some gaping and moribund specimens of cockles. Numerous haemocytes and host cell debris were present in the host tissues, which seemed to be in an advanced state of lysis (Figs. 1 \& 2).

The amoebas were uninucleate, reached a diameter of 18 to $20 \mu \mathrm{m}$ and contained a spherical nucleus approximately $5 \mu \mathrm{m}$ in diameter. The nucleolus was prominent, about $3 \mu \mathrm{m}$ in diameter (Figs, 1 to 3 ), and composed of compact fibrillar and granular components (Figs. $3 \& 4$ ). Several oval to spherical electrondense masses resembling the dense fibrilar component of the nucleolus were observed. The masses were frequently found to be adhering to both the nuclear and cytoplasmic sides of the nuclear membrane and occasionally in close contact with cytoplasmic organelles (Figs. $3 \& 4$ ).

The nucleoli were the most prominent nuclear figures observed in these cells. The ultrastructural organization of the fibrillar and granular components of the nucleolus, and the enormous size attained by the organelle, suggest that it may be the locus of active rRNA synthesis. The dense extra-nucleolar bodies situated at the periphery of the nuclear envelope may represent a nucleolar segregation, i.e. a structure similar to the nucleolar-like bodies (nuages) observed in other cell types (Azevedo 1984). The appearance of these structures suggests that they may be involved in the continuous transport of ribonucleoproteins (rRNA and proteins) necessary for ribosomal maturation (Azevedo 1984), possibly before amoeba division.

The cytoplasm contained different types of characteristic cytoplasmic structures of eukaryotic cells as 


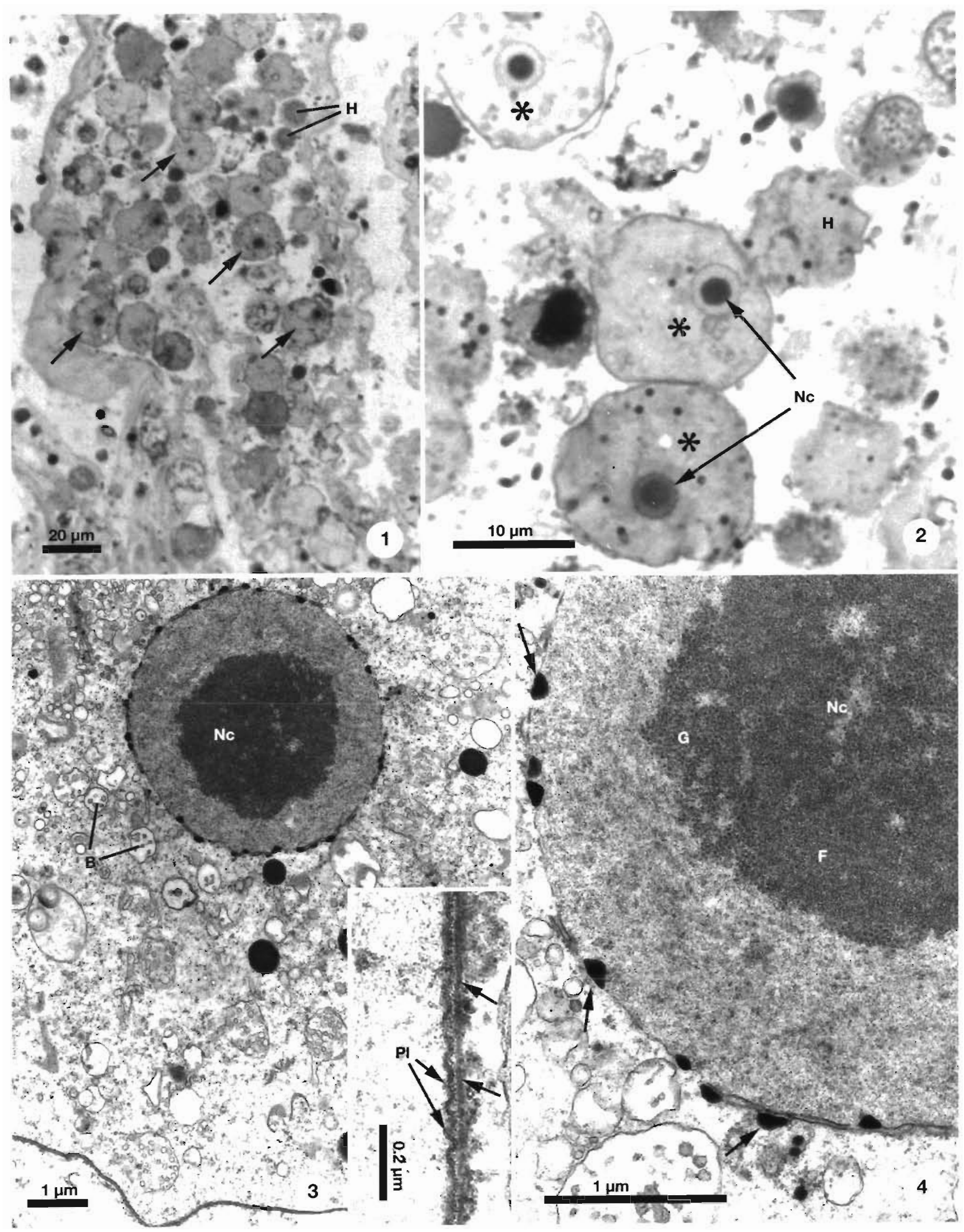


Figs. 1 to 4. Amoebas in Cerastoderma edule gills. Fig. 1. Light micrograph of cellular aggregation showing some amoebas (arrows), among haemocytes $(\mathrm{H})$. Fig. 2. Light micrograph of amoebas (*) among haemocytes $(\mathrm{H})$. The amoebas have a nucleus with a prominent nucleolus (NC). Fig. 3. Ultrathin section of an amoeba showing the nucleus with a prominent nucleolus (Nc), the cytoplasm with several structures, mainly multivesicular bodies (B), vesicles, vacuoles and lipid droplets. Inset: Detail of the plasmalemma (Pl) of an amoeba, externally surrounded by a thin wall (arrows). Fig. 4. Ultrathin section of an amoeba showing details of the nucleolus (Nc) containing fibrillar (F) and granular $(G)$ components. At the periphery of the nucleus several dense bodies (arrows) are present in close contact with the nuclear envelope, which appears to be disrupted in several places

well as numerous vesicles, vacuoles and dense bodies (Figs. 3 \& 4 ). The plasmalemma was surrounded by a thin wall (Fig. 3, inset).

The presence of cysts containing amoeboid cells was described from Crassostrea angulata (Gutiérrez 1977) and $C$. virginica (Mackin 1962). However, their morphology was very different from the cell described here. Most of the previously described amoeboid cells were observed by light microscopy (Mackin 1962, Gutiérrez 1977, Lauckner 1983), while in the present work some details were obtained by TEM. The primary differentiating features are the absence of a prominent nucleolus and the absence of dense extra-nucleolar bodies in the previously described amoebas. Such structures were observed in the present amoebas (Figs. $3 \& 4$ ). Spindle-shaped amoebas containing thread-like extensions of the cytoplasm, as are found in a proteomyxan amoeba, were never observed in the present case. The rarity with which amoebas are found in tissues of bivalve molluscs coupled with the paucity of morphological information and the lack of knowledge about the life cycles prevent any informed speculation about whether the various amoebas are identical, similar or dissimilar species.

No developmental cell stages were observed. Histopathology associated with these cells revealed haemocytic infiltration and necrosis cells that possibly led to the death of the host. I believe that the mortality of the cockle is the result of the activity of the amoebas in

Editorial responsibility: Albert Sparks, Seattle, Washington, USA contact with gill tissue and not of the action of the microsporidian hyperparasite, Unikaryon legeri, living in metacercaria found in pallial tissue near the hinge of the cockle.

The infrequency with which these amoebas have been observed has prevented me from conducting any laboratory experiments aimed at determining the lifecycle, experimentally inducing infections or determining the mode of transmission of the amoebas.

Acknowledgements. This work was partially supported by a grant from Eng ${ }^{\circ}$ A. Almeida Foundation (Porto, Portugal).

\section{LITERATURE CITED}

Azevedo C (1984) Developmental and ultrastructural autoradiographic studies of nucleolus-like bodies (nuages) in oocytes of a viviparous teleost (Xiphophorus helleri). Cell Tissue Res 238:121-128

Azevedo C, Canning EU (1987) Ultrastructure of a microsporidian hyperparasite, Unikaryon legeri (Microsporida), of trematoda larvae. J Parasitol 73:214-223

Gutiérrez M (1977) Datos sobre parasitología e histopatología del ostión, Crassostrea angulata lmK. de la costa sudatlántica de España. Invest Pesq 41:543-567

Lauckner G (1983) Diseases of Mollusca: Bivalvia. In: Kinne O (ed) Diseases of marine animals, Vol II. Biologische Anstalt Helgoland, Hamburg, p 477-961

Mackin JG (1962) Oyster disease caused by Dermocystidium marinum and other microorganisms in Louisiana. Publ Inst Mar Sci Univ Tex 7:132-229

Manuscript received: December 3, 1996

Revised version accepted: June 11, 1997 